\title{
Preferred resting surfaces of dominant malaria vectors inside different house types in rural south-eastern Tanzania
}

Betwel J. Msugupakulya 1,2* ${ }^{10}$, Emmanuel W. Kaindoa ${ }^{1,3}$, Halfan S. Ngowo ${ }^{1,4}$, Japhet M. Kihonda',

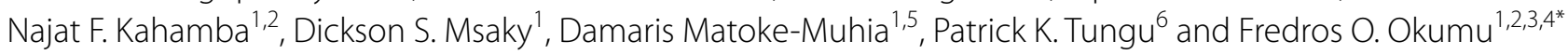

\begin{abstract}
Background: Malaria control in Africa relies extensively on indoor residual spraying (IRS) and insecticide-treated nets (ITNs). IRS typically targets mosquitoes resting on walls, and in few cases, roofs and ceilings, using contact insecticides. Unfortunately, little attention is paid to where malaria vectors actually rest indoors, and how such knowledge could be used to improve IRS. This study investigated preferred resting surfaces of two major malaria vectors, Anopheles funestus and Anopheles arabiensis, inside four common house types in rural south-eastern Tanzania.
\end{abstract}

Methods: The assessment was done inside 80 houses including: 20 with thatched roofs and mud walls, 20 with thatched roofs and un-plastered brick walls, 20 with metal roofs and un-plastered brick walls, and 20 with metal roofs and plastered brick walls, across four villages. In each house, resting mosquitoes were sampled in mornings (6 a.m.-8 a.m.), evenings (6 p.m.-8 p.m.) and at night (11 p.m.-12.00 a.m.) using Prokopack aspirators from multiple surfaces (walls, undersides of roofs, floors, furniture, utensils, clothing, curtains and bed nets).

Results: Overall, only $26 \%$ of An. funestus and $18 \%$ of An. arabiensis were found on walls. In grass-thatched houses, 33-55\% of An. funestus and 43-50\% of An. arabiensis rested under roofs, while in metal-roofed houses, only 16-20\% of An. funestus and 8-30\% of An. arabiensis rested under roofs. Considering all data together, approximately $40 \%$ of mosquitoes rested on surfaces not typically targeted by IRS, i.e. floors, furniture, utensils, clothing and bed nets. These proportions were particularly high in metal-roofed houses (47-53\% of An. funestus; 60-66\% of An. arabiensis).

Conclusion: While IRS typically uses contact insecticides to target adult mosquitoes on walls, and occasionally roofs and ceilings, significant proportions of vectors rest on surfaces not usually sprayed. This gap exceeds one-third of malaria mosquitoes in grass-thatched houses, and can reach two-thirds in metal-roofed houses. Where field operations exclude roofs during IRS, the gaps can be much greater. In conclusion, there is need for locally-obtained data on mosquito resting behaviours and how these influence the overall impact and costs of IRS. This study also emphasizes the need for alternative approaches, e.g. house screening, which broadly tackle mosquitoes beyond areas reachable by IRS and ITNS.

Keywords: Indoor residual spraying, Contact insecticides, House screening, Malaria vectors, An. funestus, An. arabiensis, Ifakara Health Institute, Indoor resting behaviours

*Correspondence: jbetwel@ihi.or.tz; fredros@ihi.or.tz

${ }^{1}$ Environmental Health and Ecological Sciences Department, Ifakara Health Institute, P. O. Box 53, Ifakara, Tanzania

Full list of author information is available at the end of the article

\section{Background}

Malaria control efforts have yielded significant success in recent decades, resulting in decline in number malaria cases from 239 million in 2010 to 219 million in 2017 [1]. The most widely used interventions, namely 
insecticide-treated nets (ITNs), indoor residual spraying (IRS) and artemisinin-based combination therapy (ACT) are credited with 663 million clinical cases of malaria averted between 2000 and 2015 [2]. In Tanzania, the impact of these interventions has been demonstrated by multiple investigators [3-6], as well as national surveys, which show significant overall reduction in burden [7]. Despite these gains, there is also evidence that the anti-malaria progress is levelling off and that the gains may be lost [1]. Between 2015 and 2017, continued utilization of the core interventions led to no significant declines in malaria at global scale [1].

To rejuvenate the malaria fight, several countries have set ambitious goals in line with the WHO Global Technical Strategy for Malaria Elimination [8], and more recently, the High Burden to High Impact initiative which targets the ten most malarious countries in Africa, plus India [9]. The new initiatives are expected to be much more aggressive and country-led but involving multiple partners. However, similar to previous efforts, these efforts are primarily reliant on ITNs [now long-lasting insecticide-treated nets (LLINs)], IRS and effective case management [1]. Despite proven effectiveness of the vector control interventions, LLINs and IRS are negatively affected by insecticide resistance $[10,11]$, increasing outdoor-biting [12-14], high costs and the sub-optimal coverage and usage at community and household level. Resistance is often associated with exposure of vectors to insecticides used in agriculture $[15]$ and public health $[16,17]$, and the indoor interventions may also induce shifts in vector biting and resting behaviours [18-20].

IRS is one of the oldest malaria interventions and was the most important component of the initial attempts at global malaria eradication in 1950s and 1960s [21, 22]. It involves applying insecticides to kill mosquitoes resting on interior walls of houses [23]. In Tanzania, it has been used intermittently since the 1960s [24], and is currently deployed in selected districts mostly in the northern regions where malaria burden remains very high [25, 26]. Across Africa, IRS is mostly promoted by the US Presidents Malaria Initiative (PMI), and currently covers 14 countries in Africa [27, 28]. According to the 2015 analysis by Bhatt et al. [2], IRS alone contributed to $10 \%$ of averted clinical malaria cases in Africa between 2000 and 2015. To counter the growing challenge of insecticide resistance [29], most countries have switched from using pyrethroids, and now rely mostly on organophosphates or carbamates, as well as some new insecticide classes such as neonicotinoids, which were recently introduced [30]. There have also been calls to introduce bed nets with multiple active ingredients or synergists as a way to tackle resistance [31-33].
While much of the focus is paid to finding new chemical actives and combinations, considerably less attention is paid to how malaria mosquitoes actually respond to the indoor interventions such as IRS and LLINs. This is despite the changing housing designs and structures across Africa [34], and the demonstrated impact of housing on vector densities and malaria transmission [35-38]. Instead indoor interventions still primarily rely on historical evidence of mosquito indoor resting habits $[39,40]$, which are now due for update in light of modern transformations [34]. A study from early 1960s in Tanzania assessed distribution of malaria vectors on sprayable surfaces inside houses compared to household possessions usually removed during IRS [39]. It was observed that less than $20 \%$ of mosquitoes rested on the possessions, and that of the remaining, sprayable surfaces, the resting populations were evenly divided between substrates [39]. In a separate study in mud huts in northern Tanzania, $56 \%$ to $70 \%$ of all resting mosquitoes were found on the walls or hanging articles, while the remaining 30\% to $40 \%$ were on the underside of the roofs [40].

Other than these early studies, such investigations have become rare, yet it is likely that mosquito behaviours and survival inside houses could change with the ongoing improvements. For example, a recent study in the Gambia demonstrated that reduced mosquito survival in metal-roofed houses may lower malaria transmission [41]. Elsewhere in East Africa, it was shown that despite higher temperatures inside houses with corrugated iron roofs, survival of mosquitoes resting indoors was same as in grass thatched houses [42].

It is, therefore, crucial to understand resting behaviours of the major malaria vectors inside houses and how much they can be affected by key indoor interventions. This way, effectiveness of techniques such as IRS can be improved, and their limitations determined. This study therefore investigated the resting behaviours of two major malaria mosquitoes (An. funestus and An. arabiensis) inside typical house types in rural south-eastern Tanzania. In this area, most malaria infections are mediated by An. funestus, even though An. arabiensis remains abundant as well $[43,44]$.

\section{Methods \\ Study area}

The study was conducted in four villages across Ulanga and Kilombero districts in south-eastern Tanzania (Fig. 1). These included, Kivukoni $(-8.2021,36.6961)$ and Tulizamoyo $(-8.3669,36.7336)$ in Ulanga district, and Sululu $(-7.9973,36.8317)$ and Ikwambi $(-7.9833$, $36.8184)$ in Kilombero district. The area is within a lowlying river valley extending $250 \mathrm{~km}$ long and up to $65 \mathrm{~km}$ wide, interspersed with villages and farmlands. It has 


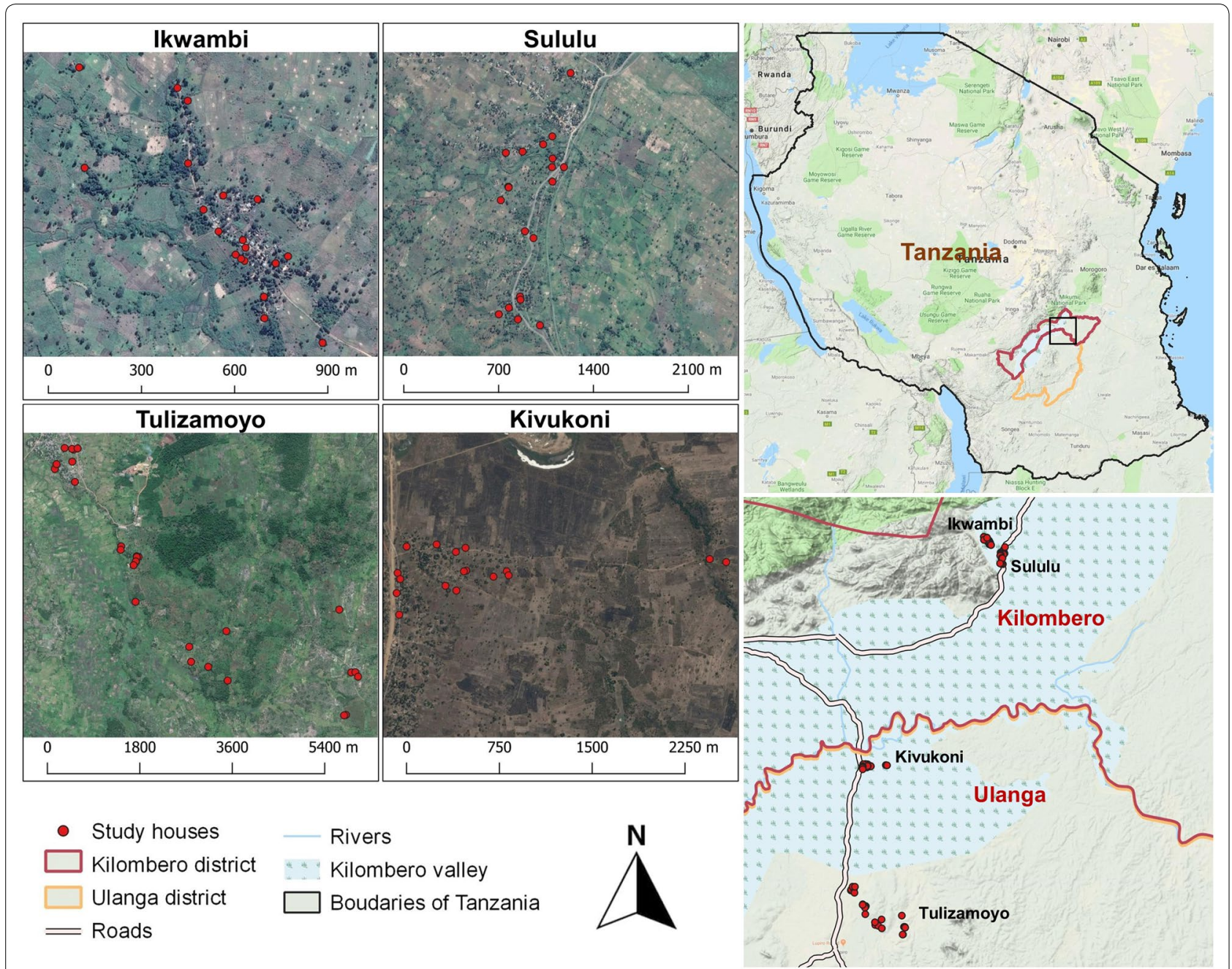

Fig. 1 Map showing study villages and study households in both Kilombero and Ulanga districts, south-eastern Tanzania. Indoor-resting mosquitoes were collected multiple times from each household during the study period

two rainy seasons, short rains between November and December and long rains between March and May, while between rainy seasons spans two dry seasons. Annual rainfall and temperatures vary from 1200 to $1800 \mathrm{~mm}$, and $16{ }^{\circ} \mathrm{C}$ to $32^{\circ} \mathrm{C}$, respectively [45]. Residents are mostly subsistence farmers, though some are also fishermen or owned small businesses.

During this study, typical house types in the villages were either thatch-roofed or metal-roofed (with corrugated iron sheets), and had either mud walls or brick walls, which were sometime plastered with concrete. Primary malaria vectors in this region are An. funestus and $A n$. arabiensis, with $A n$. funestus contributing more than $80 \%$ of current malaria transmission [44]. Culex pipiens are nuisance biters contributing $79 \%$ of all indoor biting risk [46].

\section{Selection and characterization of study houses}

Field collection of resting mosquitoes was done inside human-occupied houses, ensuring to cover the main house types. Candidate houses were selected based on construction materials for walls (mud or bricks, with or without concrete plastering) and roofs (metal or thatch). This resulted in four classes of houses (Fig. 2) commonly found in the study area, namely: (i) houses with thatched roofs and mud walls, (ii) houses with thatched roofs and brick walls (none of these houses had plastered walls), (iii) houses with metal roofs and un-plastered brick walls, and (iv) houses with metal roofs and plastered brick walls. Ceilings were uncommon and therefore excluded in this survey. All individual houses were also geo-referenced, then characterized by other attributes, namely: (a) whether eave gaps were open or closed, (b) number of 


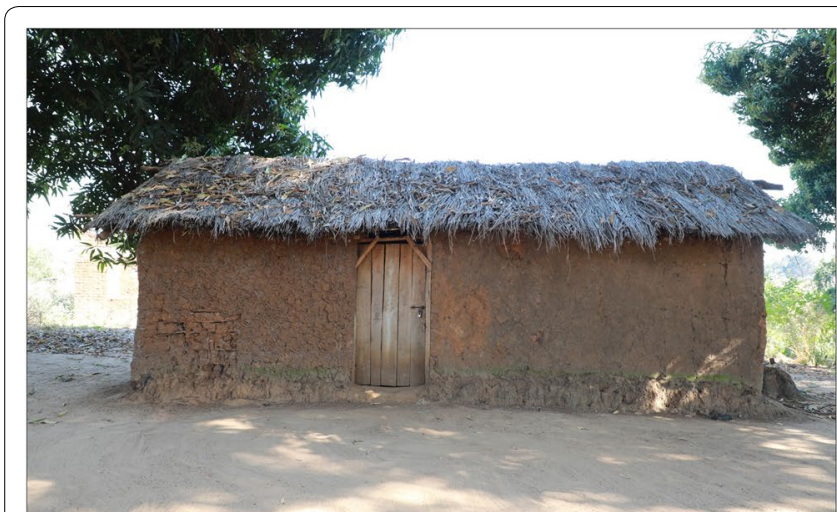

House with thatched roofs and mud walls

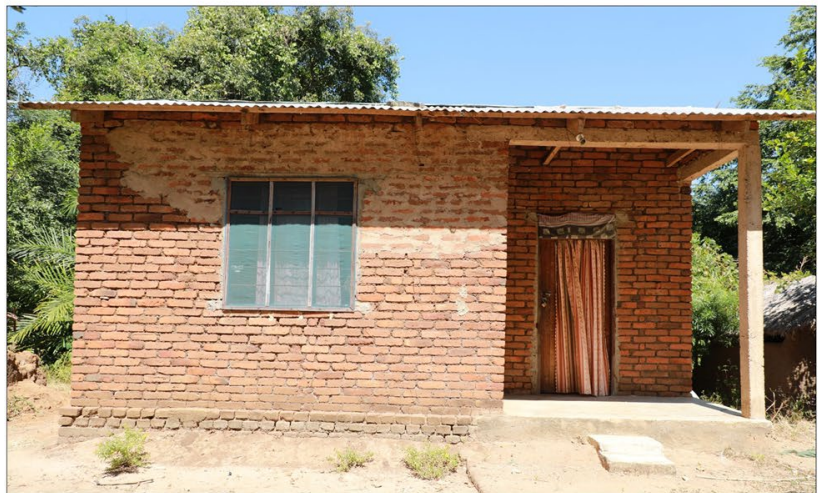

House with metal roofs and un-plastered brick walls

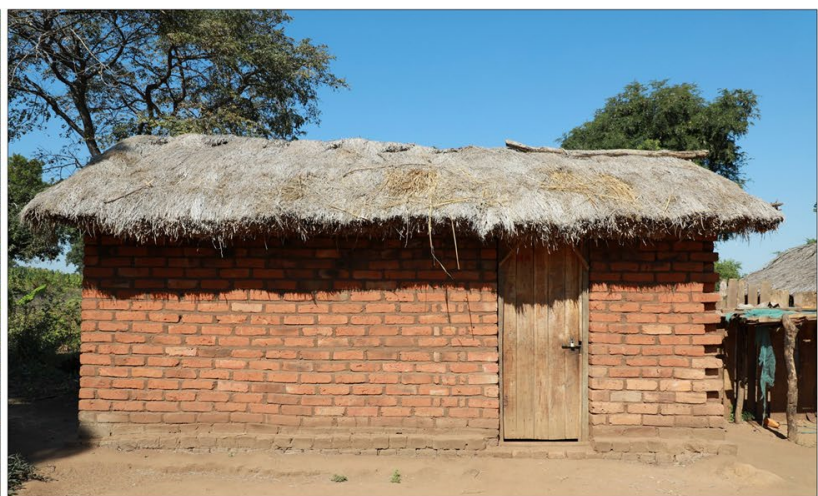

House with thatched roofs and brick walls

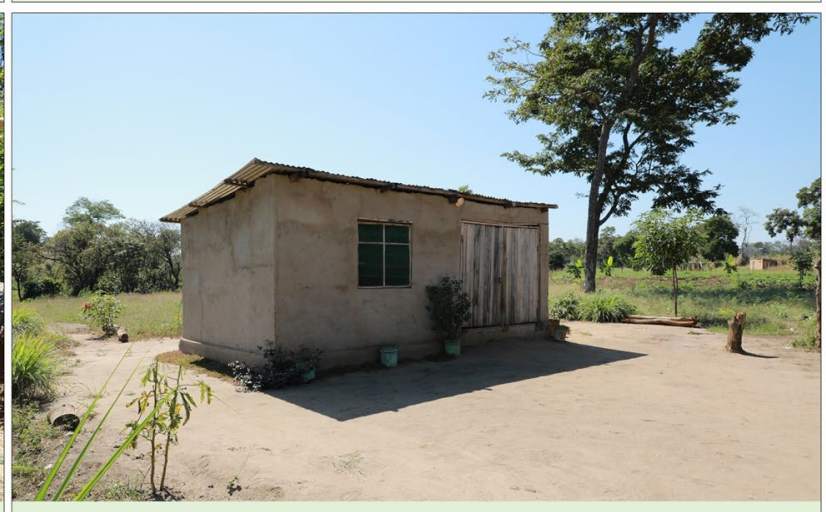

House with metal roofs and plastered brick walls

Fig. 2 Typical house types in the study villages in rural south-eastern Tanzania. The pictures depict only outside views of the houses, and does not show actual concrete plastering of some brick walls. These four are used as representative of the different house types, but the actual sizes and shapes of individual houses was varied

rooms in the house, (c) height of walls and (d) maximum daily temperatures $\left({ }^{\circ} \mathrm{C}\right)$, recorded using Tinytag ${ }^{\circledR}$ data loggers (Gemini, UK) suspended from the roofs, more than $1 \mathrm{~m}$ from the floor.

Prior to commencement of mosquito collections, 20 houses were purposively selected in each of the four villages upon consent by household heads. These included five houses per house type.

\section{Collection of mosquitoes resting on different surfaces inside the houses}

Potential mosquito resting places were identified to include: (a) walls, (b) roofs (underside of the roofs) and (c) other surfaces such as floor, clothing, bed nets and other household items. The household items were varied but generally included furniture such as beds, tables, chairs, cupboards, wood blocks, other household items such as bicycles, and utensils, wash basins, water containers, clay pots and cooking pans. The clothing included hanging garments, curtains, sacks and bags. Actual mosquito collections were done using Prokopack aspirator [47], by trained technicians. Collections involved hovering the aspirator systematically over the surfaces and collecting all mosquitoes. Lighting was provided using hand-held flash lights. The sequence of collection between resting surfaces in each room was changed to minimize sampling biases. The collections were done for 5 days each week in each village, visiting $2-4$ houses per day. Initially the collections were done between 6 a.m. and 12 p.m, from January 2019 to May 2019. Then from May to July 2019, the collections were done three times a day [in the morning (between 7:00 a.m. and 8:30 a.m.), evening (between 6:00 p.m. and 8:00 p.m.) and at night (between 12:00 a.m. and 2:00 a.m.)], to minimize variations associated with mosquitoes moving between different resting surfaces within the houses. Unlike the other collections done by trained technicians, the late evening and late-night collections were done by trained household members to avoid intrusion of their privacy.

In total, there were 277 house visits for indoor resting mosquito collections, including 76 visits to houses with thatched roofs and mud walls, 70 to houses with thatched 
roofs and brick walls, 70 to houses with corrugated iron roofs and un-plastered brick walls, and 61 visits to houses with corrugated iron roofs and plastered brick walls.

\section{Morphological identification and processing of collected mosquitoes}

Mosquitoes collected from each of the resting surfaces were placed in separate disposable cups and labelled appropriately. They were sorted by sex and taxa, then all Anopheles sorted and identified using the morphological keys [48]. Physiological status of each female Anopheles was determined as unfed, partly fed, fully fed, gravid or semi gravid. All records were kept by house, surface, house type and village.

\section{Identification of sibling species of malaria vectors, blood meal analysis and detection of Plasmodium falciparum sporozoites in the mosquitoes}

The field-collected mosquitoes were packed individually in $1.5 \mathrm{ml}$ microcentrifuge tubes (BioPointe Scientific ${ }^{\circledR}$ ) containing silica plugged with cotton wool. Sub-samples of An. funestus sensu lato (s.l.) and Anopheles gambiae s.l. females were further analysed for sibling species, Plasmodium falciparum sporozoites and blood meal sources (if the mosquitoes were blood-fed). Sibling species identification for An. funestus s.l. and An. gambiae s.l. was done using PCR protocols originally developed by Koekemoer et al. [49] and Scott et al. [50] respectively. Blood meal analysis was done using ELISA tests [51], and parasite infections detected by screening for the P. falciparum circumsporozoite proteins in salivary glands of the adult females [52]. Heat-labile non-P. falciparum were eliminated by boiling the ELISA lysates at $100{ }^{\circ} \mathrm{C}$ for $10 \mathrm{~min}$ to remove false positives [53].

\section{Determination of physiological ages of mosquitoes}

Parity of mosquitoes was approximated following procedure described by Detinova [54] as a proxy of physiological age of mosquitoes. A subsample of non-blood fed, $A n$. funestus and An. arabiensis, were first immobilized in a refrigerator. Under stereo microscope abdomens of anesthetized mosquitoes were dissected to extract ovaries. Ovaries were examined under compound microscope to determine whether mosquitoes had laid eggs or not.

\section{Data analysis}

Data analysis was done using open source statistical software, R version 3.6.0 [55]. Generalized linear mixed effects models (GLMM) were built using functions within the lme4 package [56] to assess: (i) preferences of mosquitoes (An. funestus, An. arabiensis and Culex) for different resting surfaces and (ii) relationships between various household risk factors and number of mosquitoes caught on different surfaces. Initially, the number of female mosquitoes of each species was modelled as a response variable against resting surfaces as a fixed factor. Since walls are typically the main target for insecticide spraying, they were used as reference against which other surfaces were compared.

To assess relationships between household risk factors and mosquitoes resting on different surfaces, the number of mosquitoes caught from each surface was modelled as function of: (i) roof type, (ii) wall type, (iii) whether interior walls were plastered with cement or not, (iv) eave gaps, (v) number of rooms, (vi) wall height and (vii) daily maximum temperatures inside the houses.

In all models, households nested within villages and sampling days were used as random terms, to capture unexplained variations, and account for pseudo-replication. Poison distribution was used when fitting GLMM models, except when overdispersion was detected, in which cases, negative binomial distribution was used instead. The best fitting models were selected using Akaike Information Criterion (AIC) [57], and results presented as relative rate ratios (RR) at 95\% confidence intervals. In addition, the dabestr package for estimation statistics [58], was used to depict effect sizes of differences in mean numbers (at 95\% confidence intervals) of mosquitoes collected on different resting surfaces relative to walls.

\section{Results}

Descriptive summary of mosquitoes caught in the surveys A total of 17,870 female mosquitoes were collected, of which $31.1 \%(\mathrm{n}=5564)$ were Anopheles mosquitoes and $68.9 \%(\mathrm{n}=12,306)$ were culicines. Among Anopheles mosquitoes, $81.5 \%(\mathrm{n}=4535)$ were $A n$. funestus s.l., $17.6 \%(\mathrm{n}=977)$ were $A n$. arabiensis and $0.9 \%(\mathrm{n}=52)$ were other Anopheles species including Anopheles coustani and Anopheles pharoensis. The majority of An. funestus (72.4\%), An. arabiensis (87.8\%) and Culex (58.0\%) were collected in thatch-roofed houses.

\section{Resting preferences of mosquitoes inside the houses}

There was an uneven distribution of mosquitoes between the four house types and between the different resting surfaces (Tables 1, 2 and Fig. 3). Only 26.1\% of $A n$. funestus, $18.2 \%$ of An. arabiensis and $27.9 \%$ of Culex mosquitoes rested on walls. Proportions resting on the undersides of the roofs included $32.9 \%$ of $A n$. funestus, $42 \%$ of $A n$. arabiensis and $33.6 \%$ of Culex mosquitoes. Surprisingly, as many as $41 \%$ An. funestus, $40 \%$ of $A n$. arabiensis and $39 \%$ of Culex mosquitoes rested on surfaces other than either the walls or roofs, i.e. surfaces that are not typically sprayed during IRS. The actual distribution of the two malaria vector species and the Culex 
Table 1 Numbers and percentages of mosquitoes of different species collected from different surfaces inside houses of different types in Ulanga and Kilombero districts, south-eastern Tanzania

\begin{tabular}{|c|c|c|c|c|c|c|}
\hline \multirow[t]{2}{*}{ Species } & \multirow[t]{2}{*}{$\begin{array}{l}\text { Resting surfaces } \\
\text { inside houses }\end{array}$} & \multirow{2}{*}{$\begin{array}{l}\text { Thatched roofs } \\
\text { and mud walls } \\
\text { n (\%) }\end{array}$} & \multirow{2}{*}{$\begin{array}{l}\text { Thatched roofs } \\
\text { and brick walls } \\
\text { n (\%) }\end{array}$} & \multirow{2}{*}{$\begin{array}{l}\text { Metal roofs } \\
\text { and un-plastered brick } \\
\text { walls } \\
\text { n (\%) }\end{array}$} & \multirow{2}{*}{$\begin{array}{l}\text { Metal roofs } \\
\text { and plastered brick } \\
\text { walls } \\
\text { n (\%) }\end{array}$} & \multirow{2}{*}{$\begin{array}{l}\text { Totals } \\
\text { N (\%) }\end{array}$} \\
\hline & & & & & & \\
\hline \multirow[t]{4}{*}{ Anopheles funestus } & Walls & $168(17.9)$ & $573(24.5)$ & $385(37.1)$ & $59(27.4)$ & $1185(26.1)$ \\
\hline & Roofs & $519(55.2)$ & $762(32.5)$ & $166(16.0)$ & $43(20.0)$ & $1490(32.9)$ \\
\hline & Other surfaces & $253(26.9)$ & $1008(43.0)$ & $486(46.9)$ & $113(52.6)$ & $1860(41.0)$ \\
\hline & Total & 940 & 2343 & 1037 & 215 & 4535 \\
\hline \multirow[t]{4}{*}{ Anopheles arabiensis } & Walls & $111(21.0)$ & $42(12.7)$ & $21(26.6)$ & $4(10.0)$ & 178 (18.2) \\
\hline & Roofs & $227(43.1)$ & $165(49.8)$ & $6(7.6)$ & $12(30.0)$ & $410(42.0)$ \\
\hline & Other surfaces & $189(35.9)$ & $124(37.5)$ & $52(65.8)$ & $24(60.0)$ & 389 (39.8) \\
\hline & Total & 527 & 331 & 79 & 40 & 977 \\
\hline \multirow[t]{4}{*}{ Culex mosquitoes } & Walls & $1089(25.2)$ & $700(25.4)$ & $683(32.2)$ & $929(31.1)$ & 3401 (27.9) \\
\hline & Roofs & $1926(44.6)$ & $1352(49.0)$ & $389(18.3)$ & $431(14.4)$ & 4098 (33.6) \\
\hline & Other surfaces & 1300 (30.1) & 707 (25.6) & 1051 (49.5) & $1630(54.5)$ & 4688 (38.5) \\
\hline & Total & 4315 & 2759 & 2123 & 2990 & 12,187 \\
\hline
\end{tabular}

mosquitoes also depended on house construction materials. Nearly $80 \%$ of An. funestus and An. arabiensis were collected in grass-thatched houses and the remainder in the metal-roofed houses. However, once inside the houses, proportions resting under the roof surfaces was generally lower in metal-roofed houses (An. funestus, 16.0-20.0\%; An. arabiensis, 7.6-30.0\%) than in grassthatched houses (An. funestus, 32.5-55.2\%; An. arabiensis, 43.1-49.8\%). The proportions of mosquitoes resting on surfaces not typically sprayed were approximately one-third in grass-thatched houses, and between one half and two-third in metal-roofed houses. Full details including distribution of Culex mosquitoes are shown in Table 1.

Table 2 shows the extent to which mosquitoes preferred roofs and other internal house surfaces, compared to walls. Generally, the proportion of mosquitoes resting on non-sprayed surfaces (other surfaces) was always higher than proportions resting on walls regardless of house type. However, proportions resting on roofs was higher than on walls for grass-thatched houses, but lower for metal-roofed houses (Table 2).

When the data was examined for different house types, it became clear that wall surfaces, at best had only onethird of mosquitoes resting. Depending on house construction materials, proportions of mosquitoes resting on roofs and other surfaces was often higher than on walls, except in metal-roofed houses, where walls tended to harbour more mosquitoes (Figs. 4 and 5). Data for Culex mosquitoes is shown in Tables 1 and 2, and in Additional file 1 . When the other surfaces were examined in detail, it was observed that significant proportions of mosquitoes on these surfaces were resting on bed nets, floors, and on furniture, but also on hanging clothes. Full details are provided in Table 3.

When interaction was assessed between time of collection and number of resting mosquitoes. Significant interaction was observed between number of An. funestus resting on roof in the evening. There was no any other significant interaction between time of collection and number of resting mosquitoes (Additional file 1: Table S1).

\section{Effects of household variables on preferences of mosquitoes for different resting surfaces inside houses} Associations between household risk factors and proportions of mosquitoes in different resting surfaces are summarized in Table 4. Generally, compared to metal-roofed houses, grass-thatched houses had more mosquitoes of all taxa, and on all surfaces. In most cases, the number of mosquitoes in grass-thatched houses was more than double that in metal-roofed houses. Compared to brick walled houses, the mud-walled houses had less mosquitoes of all taxa, on any surface assessed. These differences varied but were significantly four times less for $A n$. funestus $(\mathrm{p}=0.01)$ (Table 4). Leaving walls un-plastered was also associated with greater Anopheles density on the walls, significantly more so with An. funestus. This effect was less evident when considering mosquitoes collected from roofs or other surfaces. Similarly, leaving the eave spaces open was associated with higher vector densities on the walls and other surfaces, but not on roofs. Finally, there were more mosquitoes on walls below one metre. Full details are provided in Table 4. 


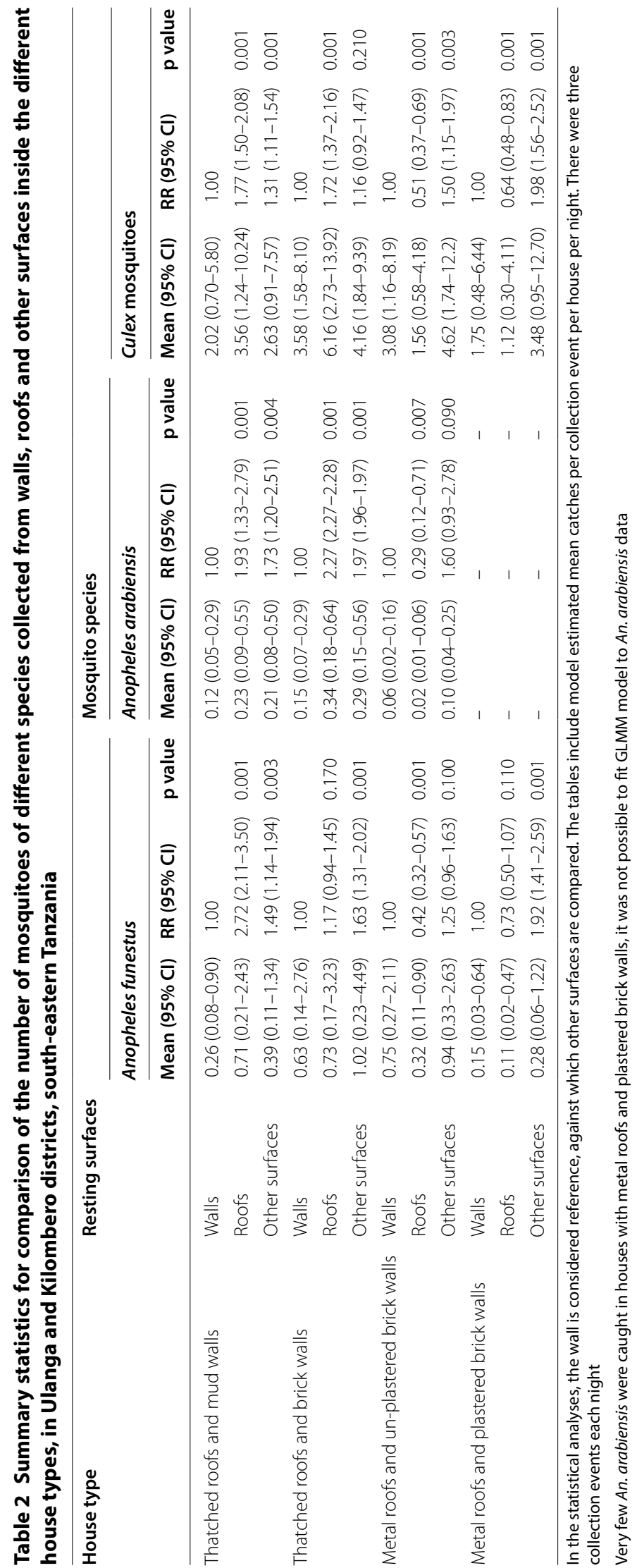




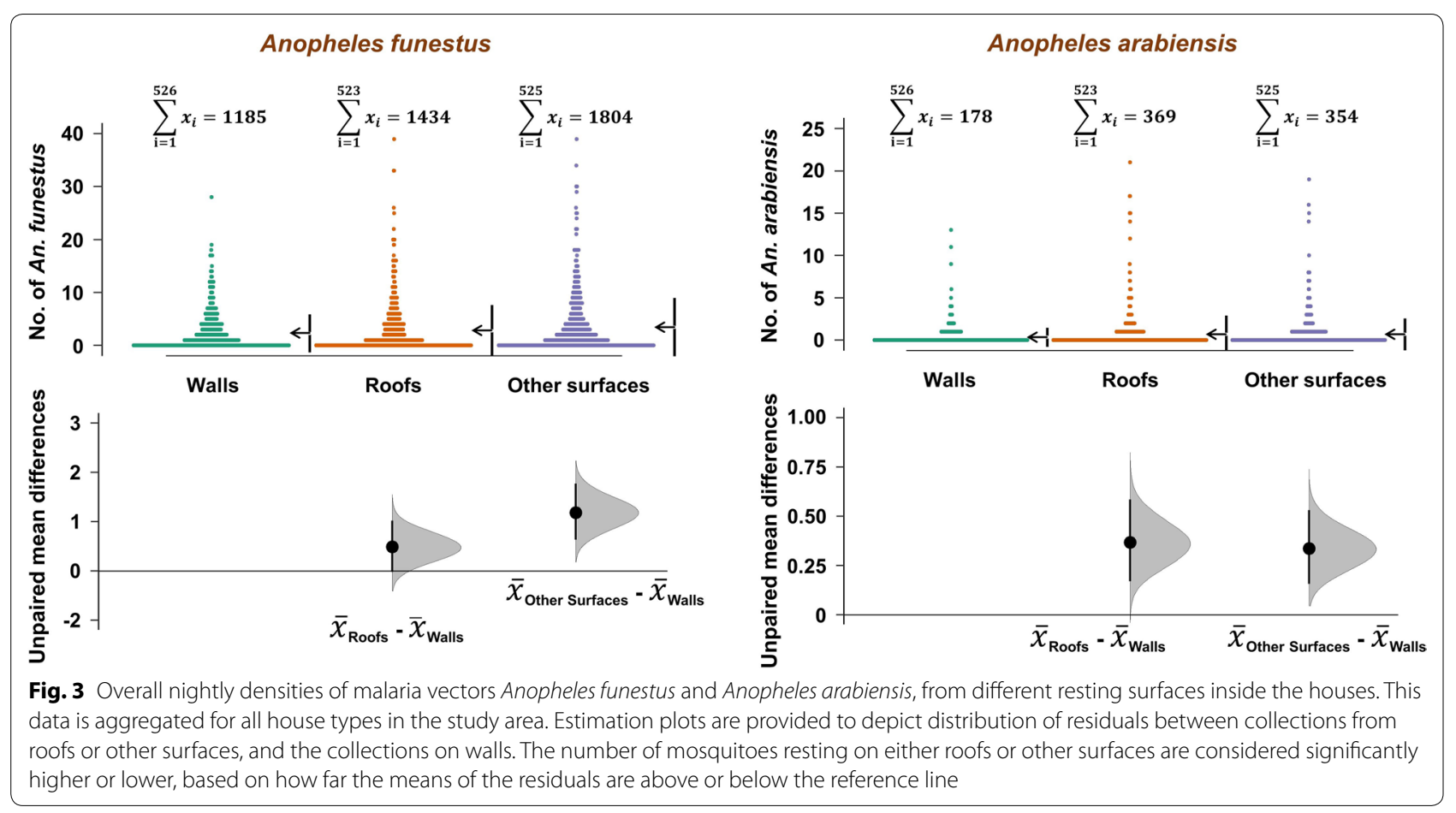

\section{Anopheles sibling species and Plasmodium infections}

A subsample of 191 An. gambiae s.l. and 623 An. funestus s.l. were assayed for identification of sibling species, and presence of infectious stages of $P$. falciparum, i.e. sporozoites in the salivary glands. In the An. gambiae s.l. samples, there was an overall PCR amplification of 93.2\% ( $\mathrm{n}=178)$, of which $100 \%$ were An. arabiensis, and none had sporozoite infections. For An. funestus s.l., PCR amplification was $89.1 \%(\mathrm{n}=555)$, of which $93.1 \%$ were An. funestus sensu stricto (s.s.) $(\mathrm{n}=517)$, and $6.8 \%$ were Anopheles rivulorum $(\mathrm{n}=38)$. None of the An. rivolurum, nor the un-amplified samples had sporozoites infections, but four of the An. funestus s.s. were sporozoite positive $(0.8 \%)$.

\section{Mosquito blood meal sources and parity statuses}

Based on the blood-meal ELISA assays done on 45 blood-fed $A n$. arabiensis, more than half had human blood (55.56\%; $\mathrm{n}=25)$. The rest had blood from cattle $(20 \% ; n=9), \operatorname{dogs}(15.6 \% ; n=7)$, chickens $(2.2 \% ; n=1)$ as well as mixed blood from dogs and cattle $(4.4 \% ; \mathrm{n}=2)$ and from humans and dogs $(2.2 \% ; \mathrm{n}=1)$. For $A n$. funestus s.s., 224 blood-fed females were tested, the majority of which had obtained blood from humans $(90.6 \% ; n=203)$. The rest of the $A n$. funestus had blood from chicken $(2.2 \% ; \mathrm{n}=5)$, cattle $(1.8 \% ; \mathrm{n}=4), \operatorname{dog}(0.9 \% ; \mathrm{n}=2)$, mixtures of human and cattle blood $(2.7 \% ; n=6)$ or human and chicken blood (1.8\%; $\mathrm{n}=4)$. Lastly, for An. rivulorum, only seven samples were tested, six of which had human blood in their guts $(85.7 \%)$, the other having fed on cattle (14.3\%). Of 67 An. arabiensis dissected, 53.7\% $(\mathrm{n}=36)$ were parous and $46.3 \%(n=31)$ were nulliparous. While of $160 \mathrm{An}$. funestus dissected, only $36.9 \%(\mathrm{n}=59)$ were parous and the rest were nulliparous.

\section{Discussion}

This research investigated the resting behaviours of malaria mosquitoes inside typical house types in rural south-eastern Tanzanian villages where An. arabiensis and $A n$. funestus are the main vectors, the latter contributing more than $80 \%$ of all cases [44]. The main finding was that consistently less than one-third of mosquitoes that enter houses typically rest on walls, which are the main target for IRS campaigns. In fact, significant proportions regularly rest on surfaces other than walls or roofs (which are also sometime sprayed). These other surfaces include household items such as furniture, utensils, clothing and also on floors, places that are rarely sprayed. As historically observed [39, 40], this current study determined that malaria vectors do not rest only on walls, where they can be targeted with IRS. Instead, all surfaces inside houses are potential resting site for mosquitoes. The majority of An. funestus and An. arabiensis rest on surfaces other than walls, such as on the underside of roofs, bed nets, floors, furniture, utensils and clothes. However, variations were observed between vector species and house designs. In addition, assessment 


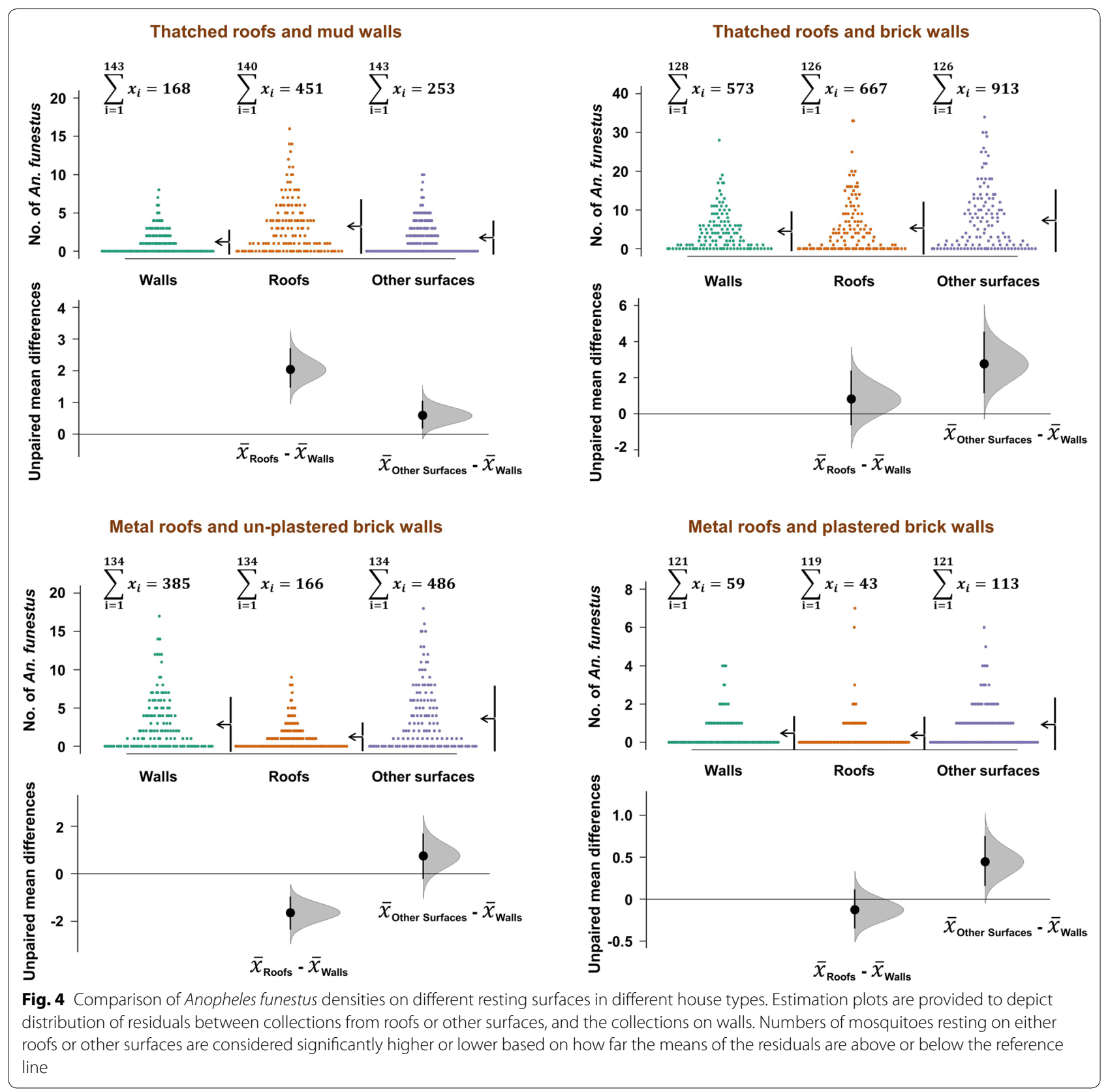

of interaction between resting surfaces and time of collection suggested that the time of collection had little to no effect on resting preference of mosquitoes (Additional file 1).

Indoor residual spraying (IRS) and long-lasting insecticide-treated nets (LLINs), despite having been tremendously impactful [2], are now perceived as inadequate for the goal of malaria elimination [5961], partly due to the rise of insecticide resistance $[10,11]$ and changes in mosquito biting behaviours $[12-14]$. These challenges may result from, and can be compounded by extensive and improper implementation of the insecticide based strategies [16-18]. For example, incomplete coverage of all mosquito resting surfaces with IRS inside houses could lead to lower coverage of indoor surfaces with insecticides, suboptimal dosing of the mosquitoes and hence reduced communal impact of the interventions. Therefore, to attain malaria elimination targets, current interventions need improvements to maximize effectiveness. This requires extensive understanding of mosquito behaviours inside houses, and how these mosquitoes 


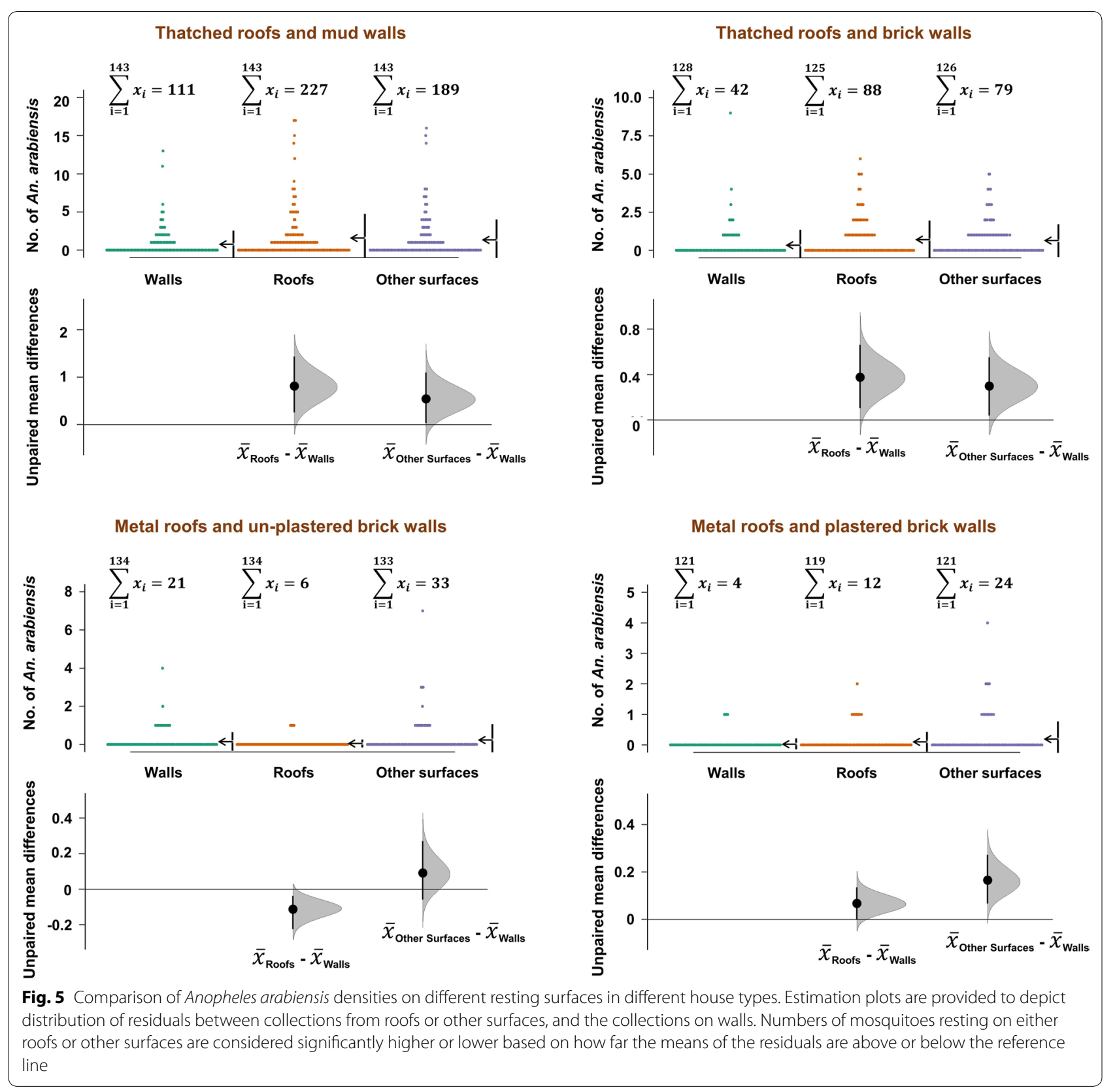

would respond to indoor interventions, notably IRS and ITNs.

The composition of indoor resting mosquitoes observed in this study was of fairly different physiological ages and few infectious Anopheles. Also, the bloodmeal sources suggest that even outdoor biting mosquitoes rested indoor. This study, therefore, suggests that expanding target surfaces inside houses when spraying insecticides would increase impact of IRS on mosquito populations. Where this is not possible, a behaviour change communication programme can be implemented to sensitize and educate people on dangers of mosquitoes resting indoors on surfaces such as hanging clothes and darkened surfaces inside the homes. The study will also enable implementers to select the most important surfaces for IRS, in cases where resources are limited. IRS campaigns usually involve removal of household items before spraying is conducted [23]. However, once these items are returned to the houses, they form important resting surfaces free of insecticides. Since the study involved multiple collections at different times of day and night, the observed resting patterns are likely the 
Table 3 Numbers and percentages of mosquitoes of different species collected from surfaces typically not targeted by IRS inside houses of different types, in Ulanga and Kilombero districts, south-eastern Tanzania

\begin{tabular}{|c|c|c|c|c|c|c|}
\hline \multirow[t]{2}{*}{ Species } & \multirow[t]{2}{*}{$\begin{array}{l}\text { Resting surfaces } \\
\text { inside houses }\end{array}$} & \multirow{2}{*}{$\begin{array}{l}\text { Thatched roofs } \\
\text { and mud walls } \\
\text { n (\%) }\end{array}$} & \multirow{2}{*}{$\begin{array}{l}\text { Thatched roofs } \\
\text { and brick walls } \\
\mathrm{n}(\%)\end{array}$} & \multirow{2}{*}{$\begin{array}{l}\text { Metal roofs } \\
\text { and un-plastered brick } \\
\text { walls } \\
n(\%)\end{array}$} & \multirow{2}{*}{$\begin{array}{l}\text { Metal roofs } \\
\text { and plastered brick } \\
\text { walls } \\
\mathrm{n}(\%)\end{array}$} & \multirow{2}{*}{$\begin{array}{l}\text { Totals } \\
\text { N (\%) }\end{array}$} \\
\hline & & & & & & \\
\hline \multirow[t]{6}{*}{ Anopheles funestus } & Floor & $129(12.8)$ & $29(25.7)$ & $125(25.7)$ & $48(19.0)$ & $331(17.8)$ \\
\hline & Furniture & $186(18.5)$ & $18(15.9)$ & $80(16.5)$ & $87(34.4)$ & $371(19.9)$ \\
\hline & Bed nets & $587(58.2)$ & $25(22.1)$ & $79(16.3)$ & $59(23.3)$ & $750(40.3)$ \\
\hline & Clothes & $74(7.3)$ & $31(27.4)$ & $134(27.6)$ & $32(12.6)$ & $271(14.6)$ \\
\hline & Utensils & $32(3.2)$ & $10(8.8)$ & $68(14.0)$ & $27(10.7)$ & $137(7.4)$ \\
\hline & Total & 1008 & 113 & 486 & 253 & 1860 \\
\hline \multirow[t]{6}{*}{ Anopheles arabiensis } & Floor & $25(20.2)$ & $8(33.3)$ & $16(30.8)$ & $36(19.0)$ & 85 (21.9) \\
\hline & Furniture & $18(14.5)$ & $7(29.2)$ & $6(11.5)$ & $54(28.6)$ & $85(21.9)$ \\
\hline & Bed nets & $63(50.8)$ & $1(4.2)$ & $15(28.8)$ & $24(12.7)$ & $103(26.5)$ \\
\hline & Clothes & $9(7.3)$ & $3(12.5)$ & $9(17.3)$ & $41(21.7)$ & $62(15.9)$ \\
\hline & Utensils & $9(7.3)$ & $5(20.8)$ & $6(11.5)$ & $34(18.0)$ & $54(13.9)$ \\
\hline & Total & 124 & 24 & 52 & 189 & 389 \\
\hline \multirow[t]{6}{*}{ Culex mosquitoes } & Floor & $209(29.6)$ & $458(28.1)$ & $275(26.2)$ & $261(20.1)$ & $1203(25.7)$ \\
\hline & Furniture & $189(26.7)$ & $470(28.8)$ & $191(18.2)$ & $461(35.5)$ & $1311(28.0)$ \\
\hline & Bed nets & $100(14.1)$ & $123(7.5)$ & $236(22.5)$ & $100(7.7)$ & $559(11.9)$ \\
\hline & Clothes & $125(17.7)$ & $368(22.6)$ & $175(16.7)$ & $236(18.2)$ & 904 (19.3) \\
\hline & Utensils & 84 (11.9) & $211(12.9)$ & $174(16.6)$ & $242(18.6)$ & $711(15.2)$ \\
\hline & Total & 707 & 1630 & 1051 & 1300 & 4688 \\
\hline
\end{tabular}

natural patterns. It is however unclear whether there are any frequent movements of mosquitoes between resting surfaces, and how such movements may influence overall impact of IRS.

More importantly, these findings highlight specific gaps and limitations of IRS, and the need for more comprehensive interventions such as house improvement. As an example, house screening would not be affected by mosquito resting behaviours but would instead reduce overall densities in the homes. Another way would be to expand, as much as possible, the IRS targeted surfaces to include undersides of roofs and other sprayable surfaces (such as underneath beds, tables and other furniture) to have increased impact on the mosquitoes. Thirdly, coupling IRS with strategies to minimize mosquito resting on non-sprayable surfaces might also enhance impact. Such strategies may include, but are not limited to proper storage of household items, e.g. by placing these items inside enclosures such as cupboards. This could reduce potential surfaces for mosquito to rest, which may maximize mosquito contacts with treated surfaces. Without considering surfaces other than walls, our current efforts, targeting mosquito vectors with IRS might limit the impact of IRS on elimination and control outcomes. However, it is also recognized that proportion of mosquitoes resting on surfaces other than walls does not mean that these mosquitoes would never come into contact with walls or would not be killed by IRS. For this reason, additional studies may be required to examine how these differential resting behaviours and localization of the vectors in different house types actually impact effectiveness of IRS.

Indoor residual spraying remains one of the mainstays of malaria control in Africa, and is widely popular despite high costs. It is currently promoted in Africa mostly through the US Presidents Malaria Initiative [27] and national programmes often alongside LLINs, but was historically the most dominant tool in Africa and elsewhere starting from the Global Malaria Eradication period [21, 22]. It has indeed been associated with major reductions in malaria cases in the southern Africa region in past decades [62, 63], and remains an important component of their malaria control arsenal. The spraying procedures are generally standardized to achieve scale and reduce costs [23], and generally target walls and ceilings occasionally where these exist. As a result, the spraying operations may not adequately capture the full-spectrum of resting spaces used by malaria vectors or others.

The findings of this current study are in line with previous studies on resting preference of Anopheles mosquitoes inside houses [40]. However, this study extended the mosquito collections to cover more potential sites inside human inhabited dwellings, and 
Table 4 Relationship between of household risk factors and indoor temperatures on mosquito resting preference on different surfaces

\begin{tabular}{|c|c|c|c|c|c|c|c|}
\hline & & \multicolumn{2}{|c|}{ Anopheles funestus } & \multicolumn{2}{|c|}{ Anopheles arabiensis } & \multicolumn{2}{|l|}{ Culex mosquitoes } \\
\hline & & $\mathrm{RR}(95 \% \mathrm{Cl})$ & p value & $\mathrm{RR}(95 \% \mathrm{Cl})$ & p value & $\mathrm{RR}(95 \% \mathrm{Cl})$ & p value \\
\hline \multicolumn{8}{|c|}{ Number of mosquitoes caught resting on walls } \\
\hline \multirow[t]{2}{*}{ Roof type } & Iron sheets & 1.00 & & 1.00 & & 1.00 & \\
\hline & Grass thatch & $2.20(0.87-5.56)$ & 0.090 & $1.93(0.46-8.10)$ & 0.400 & $1.04(0.43-2.46)$ & 0.940 \\
\hline \multirow[t]{2}{*}{ Wall type } & Brick & 1.00 & & 1.00 & & 1.00 & \\
\hline & Mud & $0.17(0.07-0.41)$ & 0.001 & $0.33(0.09-1.24)$ & 0.100 & $0.97(0.42-2.26)$ & 0.950 \\
\hline \multirow[t]{2}{*}{ Interior walls } & Plastered & 1.00 & & 1.00 & & 1.00 & \\
\hline & Un-plastered & $3.66(1.34-10.02)$ & 0.010 & $1.65(0.22-12.25)$ & 0.620 & $0.96(0.38-2.48)$ & 0.940 \\
\hline \multirow[t]{2}{*}{ Eave space } & Closed & 1.00 & & 1.00 & & 1.00 & \\
\hline & Open & $0.38(0.13-1.13)$ & 0.080 & $1.68(0.23-12.26)$ & 0.610 & $1.04(0.40-2.74)$ & 0.940 \\
\hline \multicolumn{2}{|l|}{ Increasing no. rooms } & $1.51(1.08-2.11)$ & 0.020 & $2.48(1.38-4.47)$ & 0.002 & $1.16(0.86-1.58)$ & 0.330 \\
\hline \multicolumn{2}{|l|}{ Increasing wall height } & $0.38(0.13-1.11)$ & 0.080 & $0.12(0.02-0.79)$ & 0.030 & $1.05(0.42-2.65)$ & 0.910 \\
\hline \multicolumn{2}{|l|}{ Increasing max. temp. } & $0.97(0.93-1.02)$ & 0.220 & $1.16(1.07-1.25)$ & 0.001 & $1.02(0.97-1.07)$ & 0.410 \\
\hline \multicolumn{8}{|c|}{ Number of mosquitoes caught resting on the underside of roofs } \\
\hline \multirow[t]{2}{*}{ Roof types } & Iron sheet & 1.00 & & 1.00 & & 1.00 & \\
\hline & Grass thatch & $6.07(1.78-20.70)$ & 0.004 & $92.16(9.90-857.94)$ & 0.001 & $3.96(1.51-10.36)$ & 0.005 \\
\hline \multirow[t]{2}{*}{ Wall type } & Brick & 1.00 & & 1.00 & & 1.00 & \\
\hline & Mud & $0.27(0.09-0.77)$ & 0.010 & $0.39(0.09-1.68)$ & 0.210 & $0.80(0.32-2.01)$ & 0.630 \\
\hline \multirow[t]{2}{*}{ Interior walls } & Plastered & 1.00 & & 1.00 & & 1.00 & \\
\hline & Un-plastered & $1.55(0.44-5.46)$ & 0.500 & $0.29(0.02-4.74)$ & 0.390 & $0.74(0.26-2.12)$ & 0.570 \\
\hline \multirow[t]{2}{*}{ Eave space } & Closed & 1.00 & & 1.00 & & 1.00 & \\
\hline & Open & $0.25(0.06-0.98)$ & 0.046 & $0.91(0.06-14.53)$ & 0.910 & $0.53(0.18-1.54)$ & 0.240 \\
\hline \multicolumn{2}{|l|}{ Increasing no. rooms } & $1.48(0.97-2.26)$ & 0.070 & $2.49(1.25-4.96)$ & 0.010 & $1.44(1.03-2.00)$ & 0.030 \\
\hline \multicolumn{2}{|l|}{ Increasing wall height } & $0.25(0.06-0.95)$ & 0.040 & $0.55(0.06-4.71)$ & 0.570 & $0.87(0.31-2.41)$ & 0.790 \\
\hline \multicolumn{2}{|l|}{ Increasing max. temp. } & $1.02(0.97-1.07)$ & 0.410 & $1.13(1.06-1.20)$ & 0.001 & $0.98(0.93-1.02)$ & 0.300 \\
\hline \multicolumn{8}{|c|}{ Number of mosquitoes caught resting on other surfaces inside the houses } \\
\hline \multirow[t]{2}{*}{ Roof types } & Iron sheet & 1.00 & & 1.00 & & 1.00 & \\
\hline & Grass thatch & $2.12(0.85-5.31)$ & 0.110 & $3.75(0.88-16.03)$ & 0.070 & $1.66(0.68-4.02)$ & 0.260 \\
\hline \multirow[t]{2}{*}{ Wall type } & Brick & 1.00 & & 1.00 & & 1.00 & \\
\hline & Mud & $0.22(0.09-0.55)$ & 0.001 & $0.59(0.13-2.78)$ & 0.510 & $0.92(0.38-2.21)$ & 0.840 \\
\hline \multirow[t]{2}{*}{ Interior walls } & Plastered & 1.00 & & 1.00 & & 1.00 & \\
\hline & Un-plastered & $0.92(0.33-2.54)$ & 0.870 & $2.77(0.44-17.51)$ & 0.280 & $0.81(0.30-2.13)$ & 0.660 \\
\hline \multirow[t]{2}{*}{ Eave space } & Closed & 1.00 & & 1.00 & & 1.00 & \\
\hline & Open & $2.91(1.00-8.46)$ & 0.049 & $1.95(0.28-13.71)$ & 0.500 & $1.23(0.46-3.33)$ & 0.680 \\
\hline Increasing No. rooms & & $1.16(0.84-1.60)$ & 0.370 & $1.61(0.90-2.88)$ & 0.110 & $1.25(0.91-1.71)$ & 0.160 \\
\hline Increasing wall height & & $0.84(0.29-2.41)$ & 0.750 & $2.68(0.46-15.65)$ & 0.270 & $3.18(1.21-8.33)$ & 0.020 \\
\hline Increasing max. temp. & & $0.93(0.90-0.97)$ & 0.001 & $1.12(1.06-1.19)$ & 0.001 & $1.03(0.98-1.08)$ & 0.280 \\
\hline
\end{tabular}

also examined differences between different house types. It also described relationships between house designs and microclimate, with resting preferences of the An. funestus, An. arabiensis, and Culex mosquitoes. For example, grass thatched roofs were associated with higher proportions of An. funestus on roofs. When houses had open eaves, proportion of An. funestus increased on other surfaces, but increase in indoor maximum temperature was associated with decrease in proportion of An. funestus on other surfaces.

Insecticide resistance has led to shift of insecticides used in IRS to non-pyrethroid insecticides such as pirimiphos-methyl and neonicotinoids [1, 10]. However, recently a countrywide survey in Tanzania detected resistance against pirimiphos-methyl in several sites within the country [64]. The current IRS practices clearly 
miss several surfaces where mosquitoes rest, a situation, which could exacerbate the challenge of insecticide resistance and further compromise IRS. As mentioned earlier in this paper, understanding the resting behaviours of malaria vectors is crucial, if at all IRS is going to be widely used in malaria endemic countries including Tanzania. The gaps identified in this study can be compounded by insecticide resistance, and therefore need urgent attention to ensured effectiveness.

Though mostly successful, this study also had a few limitations. First, most collections of mosquitoes were done in the morning, when people were active participating in household chores. This might have influenced the choice of mosquitoes on resting surfaces during the day. Collections during the day might also have underestimated mosquitoes resting on surfaces such as floors and utensils. Second, the type and number of possessions inside houses are related to house types, since both are linked to wealthy/income. Mud houses are unlikely to have bigger furniture and rarely items inside these houses are properly arranged. It is likely that resting patterns of mosquitoes between individual house type was influenced by type and number of surfaces inside houses. Thus, influencing observed differences in resting preference among house types involved. Unfortunately, this phenomenon was not assessed in this study. Third, this study was conducted in villages which are not protected with IRS. However, mosquitoes have been shown in multiple studies to change their behaviours with interventions. Therefore, it is important that future studies should be carried-out to assess indoor resting preference of mosquitoes in houses protected with IRS.

\section{Conclusion}

This study has demonstrated that while IRS typically uses contact insecticides against adult mosquitoes on walls, and occasionally roofs and ceilings, significant proportions of malaria vectors rest on other surfaces not usually sprayed during IRS campaigns. The study also demonstrates that the spraying gaps are influenced by house designs. For example, in grass-thatched houses, up to one-third of mosquitoes consistently rest on surfaces other than walls or roofs, are therefore not effectively controlled by contact insecticides. These gaps can reach two-thirds of mosquitoes in metal-roofed houses. It remains unclear how the observed mosquito habits could impact overall effectiveness of IRS. However, there is need to incorporate locally-obtained data on mosquito resting behaviours to maximize potential of IRS. Besides, other interventions such as improved housing should be prioritized to more comprehensively tackle indoor-biting and indoor-resting mosquitoes. Expanding IRS targeted surfaces inside houses can also be impactful. However, given the costs of IRS and logistical challenges associated with spraying non-standard surfaces, this approach in resource limited settings may not sustainable.

\section{Supplementary information}

Supplementary information accompanies this paper at https://doi. org/10.1186/s12936-020-3108-0.

Additional file 1: Figure S1. Overall densities of Culex mosquitoes, from different resting surfaces in houses. This data is aggregated for all house types in the study area. Estimation plots are provided to depict distribution of residuals between collections from roofs or other surfaces, and the collections on walls. The number of mosquitoes resting on either roofs or other surfaces are considered significantly higher or lower based on how far the means of the residuals are above or below the reference line. Figure S2. Comparison of densities of Culex mosquitoes, from different resting surfaces in different house types. Estimation plots are provided to depict distribution of residuals between collections from roofs or other surfaces, and the collections on walls. The number of mosquitoes resting on either roofs or other surfaces are considered significantly higher or lower based on how far the means of the residuals are above or below the reference line. Table S1. Summary statistics of interactions between mosquitoes of different species collected from different resting surfaces (walls, roofs and other surfaces) and time.

\section{Abbreviations}

ACT: artemisinin-based combination therapy; AIC: Akaike information criterion; ELISA: enzyme-linked immunosorbent assay; GLMM: generalized linear mixed effects model; HHMI: Howard Hughes Medical Institute; IHI: Ifakara Health institute; IRS: indoor residual spraying; ITN: insecticide-treated net; LLIN: long-lasting insecticide-treated net; PCR: polymerase chain reaction; PMI: President's Malaria Initiative; RR: relative rate ate ratio; WHO: World Health Organization.

\section{Acknowledgements}

We thank local administration and communities of Kilombero and Ulanga Districts for allowing us to work within their areas and houses. We thank volunteers who helped us in engaging the community: Hassan Ngege, Kado Ligawandu, Mussa Kinjengalile, and Maxcelin Ngakuka. We especially thank Hamza Nambongo, Kilumite Nambongo, Bakari Rajabu, Zakaria Ngelela, Khalid Kaulawa for helping in collection of mosquitoes in their houses during night times. We also direct our gratitude to research team members of outdoor mosquito control group (OMC) at Ifakara Health Institute: Arnold Mmbando, Marcelina Finda, Ismail Nambunga, Doreen Josen, Issa Mshani, Pinda Polius, Alex Limwagu, Emmanuel Happe and Elihaika Minja, for their scientific inputs and support in the implementation of this study and in editing early drafts of this report. We also thank Ms. Rukiyah Mohammed for administrative assistance throughout this study. We thank Hassan Kipongo for his devotion in sample preparation for laboratory analysis. We also direct our special gratitude to Said Abbas, Francis Tumbo and Faraji Abilah for assisting with the PCR and ELISA analyses.

\section{Authors' contributions}

BJM, FOO, and PKT conceived the study, BJM, FOO, PKT and EKW developed the study protocol. BJM and JMK carried-out data collection. BJM, FOO, HSN DSM carried out statistical analyses. BJM wrote the first draft of manuscript. HSN, EWK, NFK, DMM and PKT reviewed and edited drafts of the manuscript. $\mathrm{BJM}$, and FOO wrote the final manuscript. All authors read and approved the final manuscript.

\section{Funding}

This study was supported by Ifakara Health Institute (Training and Capacity Building Department) as part of the Msc Studentship awarded to BJM, and Howard Hughes Medical Institute (HHMI)_Gates International Research Scholarship awarded to FOO (Grant No. OPP1099295). The funders had no role in the design, data collection, analysis, interpretation of the results, preparation of manuscript or decision to publish. 


\section{Availability of data and materials}

The datasets used and/or analysed during the current study are available from the corresponding author upon reasonable request.

\section{Ethics approval and consent to participate}

Detailed explanations on aim, procedures, potential risks and benefits of the study was provided to household occupants before study commencement. Written informed consent in local language (Swahili) were obtained from household heads before inclusion in the surveys. Ethical approval for the study was granted by Institutional Review Board of Ifakara Health Institute (IHI/IRB/No: 007-2018) and the Medical Research Coordination Committee of the National Institute for Medical Research in Tanzania (NIMR/HQ/R.8a/Nol. IX/2895).

\section{Consent for publication}

All authors read and approved final manuscript for publication. This manuscript has been approved by the National Institute for Medical Research in Tanzania (NIMR/HQ/P.12 VOL XXIX/19).

\section{Competing interests}

The authors declares that they have no competing interests.

\section{Author details}

${ }^{1}$ Environmental Health and Ecological Sciences Department, Ifakara Health Institute, P. O. Box 53, Ifakara, Tanzania. ${ }^{2}$ School of Life Science and Bioengineering, The Nelson Mandela African Institution of Science and Technology, P. O. Box 447, Arusha, Tanzania. ${ }^{3}$ School of Public Health, Faculty of Health Sciences, University of the Witwatersrand, Johannesburg, South Africa. ${ }^{4}$ Institute of Biodiversity, Animal Health and Comparative Medicine, University of Glasgow, Glasgow G12 8QQ, UK. ${ }^{5}$ Centre for Biotechnology Research and Development, Kenya Medical Research Institute, Nairobi, Kenya. ${ }^{6}$ Amani Medical Research Centre, National Institute of Medical Research, Muheza, Tanzania.

Received: 28 November 2019 Accepted: 7 January 2020

Published online: 15 January 2020

\section{References}

1. WHO. World malaria report. Geneva: World Health Organization; 2018

2. Bhatt S, Weiss DJ, Cameron E, Bisanzio D, Mappin B, Dalrymple U, et al. The effect of malaria control on Plasmodium falciparum in Africa between 2000 and 2015. Nature. 2015;526:207-11.

3. Mashauri FM, Kinung'hi SM, Kaatano GM, Magesa SM, Kishamawe C, Mwanga JR, et al. Impact of indoor residual spraying of lambda-cyhalothrin on malaria prevalence and anemia in an epidemic-prone district of Muleba, North-Western Tanzania. Am J Trop Med Hyg. 2013;88:841-9.

4. Bhattarai A, Ali AS, Kachur SP, Mårtensson A, Abbas AK, Khatib R, et al. Impact of artemisinin-based combination therapy and insecticidetreated nets on malaria burden in Zanzibar. PLoS Med. 2007;4:1784-90.

5. Selemani M, Msengwa AS, Mrema S, Shamte A, Mahande MJ, Yeates K, et al. Assessing the effects of mosquito nets on malaria mortality using a space time model: a case study of Rufiji and Ifakara Health and Demographic Surveillance System sites in rural Tanzania. Malar J. 2016;15:257.

6. Alba S, Nathan R, Schulze A, Mshinda H, Lengeler C. Child mortality patterns in rural Tanzania: an observational study on the impact of malaria control interventions. Int J Epidemiol. 2014:43:204-15.

7. National Bureau of Statistics (NBS), Office of the Chief Government Statistician (OCGS), Ministry of Health, Community Development, Gender, Elderly and Children (MOHCDGEC) [Tanzania Mainland], Ministry of Health (MOH) [Zanzibar], ICF. Tanzania Malaria Indicator Survey. Dar es Salaam, Tanzania, and Rockville, Maryland: MoHCDGEC, MoH, NBS, OCGS, ICF; 2018.

8. WHO. Global technical strategy for malaria 2016-2030. Geneva: World Health Organization; 2015.

9. WHO. High burden to high impact: a targeted malaria response. Geneva: World Health Organization; 2018.

10. Hemingway J, Ranson H, Magill A, Kolaczinski J, Fornadel C, Gimnig J, et al. Averting a malaria disaster: will insecticide resistance derail malaria control? Lancet. 2016;387:1785-8.
11. Ranson H, Lissenden N. Insecticide resistance in African Anopheles mosquitoes: a worsening situation that needs urgent action to maintain malaria control. Trends Parasitol. 2016;32:187-96.

12. Sherrard-Smith E, Skarp JE, Beale AD, Fornadel C, Norris LC, Moore SJ. Mosquito feeding behavior and how it influences residual malaria transmission across Africa. Proc Natl Acad Sci USA. 2019;116:15086-95.

13. Monroe A, Moore S, Koenker H, Lynch M, Ricotta E. Measuring and characterizing night time human behaviour as it relates to residual malaria transmission in sub-Saharan Africa: a review of the published literature. Malar J. 2019;18:6.

14. Finda MF, Moshi IR, Monroe A, Limwagu AJ, Nyoni P, Swai JK, et al. Linking human behaviours and malaria vector biting risk in south-eastern Tanzania. PLoS ONE. 2019;14:e0217414.

15. Nkya TE, Poupardin R, Laporte F, Akhouayri I, Mosha F, Magesa S, et al. Impact of agriculture on the selection of insecticide resistance in the malaria vector Anopheles gambiae: a multigenerational study in controlled cinditions. Parasit Vectors. 2014;7:480.

16. Protopopoff N, Verhaeghen K, Van Bortel W, Roelants P, Marcotty T, Baza D, et al. A significant increase in $\mathrm{kdr}$ in Anopheles gambiae is associated with an intensive vector control intervention in Burundi highlands. Trop Med Int Health. 2008;13:1479-87.

17. Stump AD, Atieli FK, Vulule JM, Besansky NJ. Dynamics of the pyrethroid knockdown resistance allele in western Kenyan populations of Anopheles gambiae in response to insecticide-treated bed net trials. Am J Trop Med Hyg. 2004;70:591-6.

18. Killeen GF, Chitnis N. Potential causes and consequences of behavioural resilience and resistance in malaria vector populations: a mathematical modelling analysis. Malar J. 2014;13:97.

19. Russell TL, Lwetoijera DW, Maliti D, Chipwaza B, Kihonda J, Charlwood JD, et al. Impact of promoting longer-lasting insecticide treatment of bed nets upon malaria transmission in a rural Tanzanian setting with preexisting high coverage of untreated nets. Malar J. 2010;9:187.

20. Moiroux N, Gomez MB, Pennetier C, Elanga E, Djènontin A, Chandre F, et al. Changes in Anopheles funestus biting behavior following universal coverage of long-lasting insecticidal nets in Benin. J Infect Dis. 2012;206:1622-9.

21. Kouznetsov RL. Malaria control by application of indoor spraying of residual insecticides in tropical Africa and its impact on community health. Trop Doct. 1977;7:81-91.

22. Nájera JA, González-Silva M, Alonso PL. Some lessons for the future from the global malaria eradication programme (1955-1969). PLoS Med. 2011:8:e1000412.

23. WHO. An operational manual for indoor residual spraying (IRS) for malaria transmission control and elimination. Geneva: World Health Organization; 2015.

24. Pringle G. Malaria in the pare area of Tanzania III The course of malaria transmission since the suspension of an experimental programme of residual insecticide spraying. Trans R Soc Trop Med Hyg. 1967;61:69-79.

25. The PMI VectorLink Project. 2018/2019 Tanzania End of Spray Report. MD: Rockville; 2019.

26. National Malaria Control Programme. National malaria strategic plan 2014-2020. Dar es Salaam; 2014.

27. U.S. President's Malaria Initiative. PMI 13th annual report to congress. Washington; 2019.

28. U.S. President's Malaria Initiative. Indoor Residual Spraying. PMI. 2019. https://www.pmi.gov/how-we-work/technical-areas/indoor-residualspraying. Accessed 10 Nov 2019.

29. WHO. Global plan for insecticide resistance management in malaria vectors. Geneva: World Health Organization; 2012.

30. WHO. Prequalification vector control. Geneva: World Health Organization; 2019. https://www.who.int/pq-vector-control/prequalified-lists/en/. Accessed 12 Oct 2019.

31. Protopopoff N, Mosha JF, Lukole E, Charlwood JD, Wright A, Mwalimu CD, et al. Effectiveness of a long-lasting piperonyl butoxide-treated insecticidal net and indoor residual spray interventions, separately and together, against malaria transmitted by pyrethroid-resistant mosquitoes: a cluster, randomised controlled, two-by-two fact. Lancet. 2018;391:1577-88.

32. Tiono AB, Ouédraogo A, Ouattara D, Bougouma EC, Coulibaly S, Diarra A, et al. Efficacy of Olyset Duo, a bednet containing pyriproxyfen and permethrin, versus a permethrin-only net against clinical malaria in 
an area with highly pyrethroid-resistant vectors in rural Burkina Faso: a cluster-randomised controlled trial. Lancet. 2018;392:569-80.

33. Gleave K, Lissenden N, Richardson M, Choi L, Ranson H. Piperonyl butox ide (PBO) combined with pyrethroids in insecticide-treated nets to prevent malaria in Africa. Cochrane Database Syst Rev. 2018;11:CD012776.

34. Tusting LS, Bisanzio D, Alabaster G, Cameron E, Cibulskis R, Davies M, et al. Mapping changes in housing in sub-Saharan Africa from 2000 to 2015. Nature. 2019;568:391-4.

35. Tusting LS, Bottomley C, Gibson H, Kleinschmidt I, Tatem AJ, Lindsay SW, et al. Housing improvements and malaria risk in sub-Saharan Africa: a multi-country analysis of survey data. PLoS Med. 2017;14:e1002234.

36. Tusting LS, Ippolito MM, Willey BA, Kleinschmidt I, Dorsey G, Gosling RD, et al. The evidence for improving housing to reduce malaria: a systematic review and meta-analysis. Malar J. 2015;14:209.

37. Kirby MJ, Ameh D, Green C, Jawara M, Milligan PJ, Snell PC, et al. Efficacy of two different house screening interventions against exposure to malaria and anaemia in children in The Gambia: a randomized controlled trial. Lancet. 2013:374:998-1009.

38. Lindsay SW, Jawara M, Paine K, Pinder M, Walraven GEL, Emerson PM. Changes in house design reduce exposure to malaria mosquitoes. Trop Med Int Health. 2003;8:512-7.

39. Smith $A$. The preferential indoor resting habits of Anopheles gambiae in the Umbugwe area of Tanganyika. East Afr Med J. 1962;39:631-5.

40. Smith A. Studies on domestic habits of Anopheles gambiae that affect its vulnerability to insecticides. East Afr Med J. 1962;39:15-24.

41. Lindsay SW, Jawara M, Mwesigwa J, Achan J, Bayoh N, Bradley J, et al. Reduced mosquito survival in metal-roof houses may contribute to a decline in malaria transmission in sub-Saharan Africa. Sci Rep. 2019;9:7770.

42. Okech BA, Gouagna LC, Knols BGJ, Kabiru EW, Killeen GF, Beier JC, et al. Influence of indoor microclimate and diet on survival of Anopheles gambiae s.s. (Diptera: Culicidae) in village house conditions in western Kenya. Int J Trop Insect Sci. 2004;24:207-12.

43. Lwetoijera DW, Harris C, Kiware SS, Dongus S, Devine GJ, McCall PJ, et al. Increasing role of Anopheles funestus and Anopheles arabiensis in malaria transmission in the Kilombero Valley, Tanzania. Malar J. 2014;13:331.

44. Kaindoa EW, Matowo NS, Ngowo HS, Mkandawile G, Mmbando A, Finda $\mathrm{M}$, et al. Interventions that effectively target Anopheles funestus mosquitoes could significantly improve control of persistent malaria transmission in south-eastern Tanzania. PLoS ONE. 2017:12:e0177807.

45. World Weather Online. Morogoro monthly climate averages. 2019. https ://www.worldweatheronline.com/morogoro-weather-averages/morog oro/tz.aspx. Accessed 22 Oct 2019.

46. Matowo NS, Abbasi S, Munhenga G, Tanner M, Mapua SA, Oullo D, et al. Fine-scale spatial and temporal variations in insecticide resistance in Culex pipiens complex mosquitoes in rural south-eastern Tanzania. Parasit Vectors. 2019;12:413.

47. Maia MF, Robinson A, John A, Mgando J, Simfukwe E, Moore SJ. Comparison of the CDC Backpack aspirator and the Prokopack aspirator for sampling indoor- and outdoor-resting mosquitoes in southern Tanzania. Parasit Vectors. 2011:4:124.

48. Gillies MT, Coetzee M. A supplement to the Anophelinae of Africa south of the Sahara (Afrotropical Region). Johannesburg: South African Medical Research Institute; 1987.
49. Koekemoer LL, Kamau L, Hunt RH, Coetzee M. A cocktail polymerase chain reaction assay to identify members of the Anopheles funestus (Diptera: Culicidae) group. Am J Trop Med Hyg. 2002;66:804-11.

50. Scott JA, Brogdon WG, Collins FH. Identification of single specimens of the Anopheles gambiae complex by the polymerase chain reaction. Am J Trop Med Hyg. 1993;49:520-9.

51. Beier JC, Perkins PV, Wirtz RA, Koros J, Diggs D, Gargan TP, et al. Bloodmeal identification by direct enzyme-linked immunosorbent assay (ELISA), tested on Anopheles (Diptera: Culicidae) in Kenya. J Med Entomol. 1988;25:9-16

52. Wirtz RA, Zavala F, Charoenvit Y, Campbell GH, Burkot TR, Schneider I, et al. Comparative testing of monoclonal antibodies against Plasmodium falciparum sporozoites for ELISA development. Bull World Health Organ. 1987:65:39-45

53. Durnez L, Van Bortel W, Denis L, Roelants P, Veracx A, Trung HD, et al. False positive circumsporozoite protein ELISA: a challenge for the estimation of the entomological inoculation rate of malaria and for vector incrimination. Malar J. 2011;10:195.

54. Detinova TS. Age-grouping methods in diptere of medical importance. Geneva: World Health Organization; 1962.

55. R Core Team. R: a language and environment for statistical computing. Vienna: R Core Team; 2019.

56. Bates D, Mächler M, Bolker BM, Walker SC. Fitting linear mixed-effects models using Ime4. J Stat Softw. 2015;67:1-48.

57. Bolker B. Ecological models and data in R. 2007.

58. Ho J, Tumkaya T, Aryal S, Choi H, Claridge-Chang A. Moving beyond $P$ values: everyday data analysis with estimation plots. Nat Methods. 2018;16:565-6.

59. The malERA Refresh Consultative Panel on Tools for Malaria Elimination. malERA: an updated research agenda for diagnostics, drugs, vaccines, and vector control in malaria elimination and eradication. PLoS Med. 2017;14:e1002455.

60. The malERA Consultative Group on Vector Control. A research agenda for malaria eradication: vector control. PLoS Med. 2011;8:e1000401.

61. Rabinovich RN, Drakeley C, Djimde AA, Hall BF, Hay SI, Hemingway J, et al. malERA: an updated research agenda for malaria elimination and eradication. PLoS Med. 2017;14:e1002456.

62. Sharp BL, Streat E, Morris N, Kunene S. Seven years of regional malaria control collaboration - Mozambique, South Africa, and Swaziland. Am J Trop Med Hyg. 2007;76:42-7.

63. Mabaso MLH, Sharp B, Lengeler C. Historical review of malarial control in southern African with emphasis on the use of indoor residual housespraying. Trop Med Int Health. 2004;9:846-56.

64. Kisinza WN, Nkya TE, Kabula B, Overgaard HJ, Massue DJ, Mageni Z, et al. Multiple insecticide resistance in Anopheles gambiae from Tanzania: a major concern for malaria vector control. Malar J. 2017;16:439.

\section{Publisher's Note}

Springer Nature remains neutral with regard to jurisdictional claims in published maps and institutional affiliations.

Ready to submit your research? Choose BMC and benefit from

- fast, convenient online submission

- thorough peer review by experienced researchers in your field

- rapid publication on acceptance

- support for research data, including large and complex data types

- gold Open Access which fosters wider collaboration and increased citations

- maximum visibility for your research: over $100 \mathrm{M}$ website views per year

At BMC, research is always in progress.

Learn more biomedcentral.com/submissions 